\title{
ABO/Rh Blood Groups and Chronic Diseases in Angolan Patients
}

\author{
Euclides Nenga Manuel Sacomboio* \\ Higher Institute of Health Sciences/Agostinho Neto University, National Institute for Health Research (INIS), Luanda, Angola
}

*Corresponding author: Euclides Nenga Manuel Sacomboio, Higher Institute of Health Sciences/Agostinho Neto University, National Institute for Health Research (INIS), Angola.

To Cite This Article: Euclides Nenga Manuel Sacomboio. ABO/Rh Blood Groups and Chronic Diseases in Angolan Patients. Am J Biomed Sci \& Res. 2021 - 13(1). AJBSR.MS.ID.001834. DOI: 10.34297/AJBSR.2021.13.001834.

Received: 眥 May 21, 2021; Published: 制 June 04, 2021

\begin{abstract}
Type $O$ blood appears to be susceptible to the incidence and severity of cholera and diarrhoea, type B is common in Iceland and India, however, in Africa more than half of the population is type 0. Preliminary data from studies developed by our team in Angola in 2020, to assess the frequency of blood groups and social conditions of hypertensive patients, showed that the most frequent blood group in this population was group B $36.4 \%$ (36/99), where the age group most affected was between 51-60 (34.3\%) years of age. Another preliminary study carried out in the same year, by our research team, to evaluate the frequency of $\mathrm{ABO} / \mathrm{Rh}$ blood groups and social conditions in patients with chronic reindeer insufficiency, showed that the majority of participants were in the 0 group $56.4 \%$ (79/140), followed by patients from healthy group A and B, who represented $20.7 \%$ $(29 / 140)$ and $17.9 \%$ (25/140) respectively, where the most affected gender was male 51.4\% (72/140) with a mean dialysis of 6.6 years. Finally, another preliminary result of a study carried out by our team in the same year, to assess the frequency of blood groups in patients with nephrotic syndrome (NS) and sickle cell anaemia (SC), found that the majority of the population belonged to the Orh+ group, representing $42 \%$ (21/50) for NS and $60 \%(30 / 50)$ for SC, followed by patients in the ABrh+ group, representing 30\% (15/50) for NS and 34\% (17/50) for SN, patients in the Arh+ and Brh+ groups, accounted for $26 \%(13 / 50)$ for NS and $6 \%$ (3/50) for SC.
\end{abstract}

Keywords: I. Blood Group ABO/Rh II. Chronic Disease III. Angolans patients.

\section{Background}

Recent studies show that blood groups may be associated with risk for certain diseases, a study showed that in certain variations in glycosyltransferases, the $\mathrm{ABO}$ blood group may increase the risk for Plasmodium falciparum infections, while group $\mathrm{O}$ appears to be protective in this type of infection, however, another study in leukemic patients reported a large number of ABO polymorphisms not yet described in the literature, with potential in the leukemogenesis process, there are still studies that report that blood groups may be associated with the incidence or prognosis of several diseases, such as gastric carcinoma, small cell lung tumour, oesophageal carcinoma, susceptibility to dermatomycosis, seborrheic dermatitis, systemic lupus erythematosus, breast cancer, among others [1,2].

The ABO system is, without a doubt, the most well-known blood group. Still, the most functionally mysterious genetic polymorphism in humans since in clinical practice, the $\mathrm{ABO}$ system is the most crucial blood group related to compatibility. Since its antigenic discovery, it has been associated with infections and other diseases that have been the subject of hundreds of publications, and some reports suggest associations with gastric cancer, hepatitis B infection, selective cholera pressure, gastrointestinal infections, malaria and other diseases [3-5].

The present short communication aims to show preliminary data from studies carried out in Angola to assess the frequency of the system $(\mathrm{ABO} / \mathrm{Rh})$ in chronic non-transmissible diseases such as hypertension and chronic renal kidney disease in adults and nephrotic syndrome and sickle cell anemia in children. These preliminary data were obtained in different studies carried out in different hospital units in Luanda/Angola, in patients already diagnosed with the diseases described above and already referred for medical follow-up in the same units, during the consultation period, patients were included in the study. after compliance 
with all ethical standards in studies involving human beings. For the clinical data found in the article, a blood sample was taken from patients in test tubes containing anticoagulant EDTA (ethylenediaminetetraacetic acid) specific for phenotyping tests on $\mathrm{ABO}$ and $\mathrm{Rh}$ blood groups and for electrophoresis examination. The determination of the blood group was performed using the microplate technique, which is an agglutination test between the patient's serum and the Anti A, Anti B and Anti D reagents in each well for the phenotypic identification of blood groups (ABO and $\mathrm{Rh}$ ). Additional information was collected through a questionnaire of open and closed questions to patients and / or those directly responsible for patients.

\section{AB0/Rh Blood Group in Hypertension}

Although there are few studies showing an association between blood groups and arterial hypertension, the results of the Framingham study and other studies indicate that the incidence of ischemic heart disease may be higher in patients with group A blood than in people with the other blood groups [6].

According to the World Health Organization (WHO), the African continent has the highest prevalence of people over 25 years of age diagnosed with arterial hypertension (46\%), in contrast to the
North American continent, which has the lowest prevalence (35\%) [7], this organization's data is impressive, because it highlights that in the world at least $30 \%$ of deaths are caused by cardiovascular diseases, and it is estimated that in Angola between 5 to $10 \%$ of the economically active population may be suffering from arterial hypertension and if there is not case control, measures to prevent disease risk factors and policies implemented properly, this problem will affect a large proportion of the Angolan population [8].

Preliminary data from a study developed by our team in January 2020, in a public tertiary hospital in Luanda, Angola to assess the frequency of blood groups and social conditions of hypertensive patients, showed that of the 99 participants the most frequent blood group of hypertensive patients is B $36.4 \%$ (36/99), the most affected age group was between 51-60 (34.3\%) years old, the female gender predominated with $72.7 \%$ (72/99), mostly single, with secondary schooling (59.6\%), from Viana 41.4\% (41/99), with more than 5 children $51.5 \%$ (51/99), trader 64.6\% (64/99), only $58.7 \%$ (58/99) of them did not consume alcohol and $57.6 \%$ (57/99) did not use table salt, 76.8\% (76/99) of them did not practice physical exercise and $81.8 \%$ (81/99) reported having no family members with hypertension (Figure 1).

\section{Hypertension/Age}

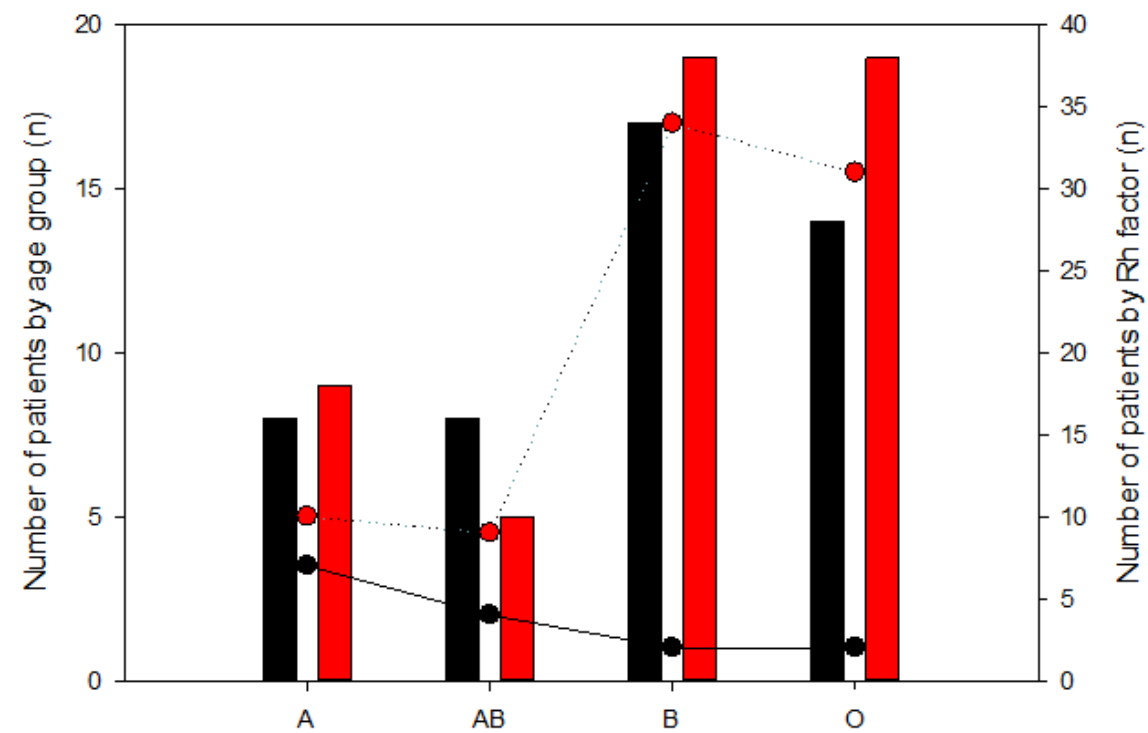

Blood Groups

Figure 1: Hypertension and blood groups: patients with arterial hypertension were classified into two groups, the first of patients under 50 years of age and the second of patients over 50 years of age, to identify the frequency of blood groups and the Rh factor. 
The incidence of hypertension can be seen as shown in the figure 1. Regarding the blood group, it was observed that blood group $\mathrm{B}-\mathrm{Rh}+$ presented $34.4 \%$ and were the majority compared to blood group $0-\mathrm{Rh}+31.3 \%$ (Figure 1); this was the first study developed by our research group, where another blood group overcomes blood group 0 , a previous study aimed to check the sickle cell trait in people undergoing hemoglobin electrophoresis, our group found that blood group 0 was about $41 \%$ of the total population and all participants in this blood group were under 41 years old [9].

\section{$\mathrm{ABO} / \mathrm{Rh}$ Blood Groups and Chronic Kidney Disease}

Blood groups have also been linked to infectious diseases, for example, it has been observed that people with type 0 blood are more susceptible to the incidence and severity of cholera and diarrhoea, while people with type B blood are less affected and these tendencies seem reflect on blood types found in the Indian subcontinent, where type $\mathrm{B}$ is common and type $\mathrm{O}$ is less common and other regions such as Iceland where there is a relatively low percentage of individuals in blood group $A$ and $A B$, and these appear to be more susceptible to epidemics of smallpox, however in Africa more than half of Africa's population is type 0 [9], a previous study by our research team, with the aim of verifying the sickle cell trait in people undergoing hemoglobin's electrophoresis, found that blood group 0 was found in about $41 \%$ of the total population [10].

The $\mathrm{ABO}$ and $\mathrm{Rh}$ systems, which have clinical importance in transfusion compatibility, can cause maternal-fectal incompatibility with the development of perinatal haemolytic disease (DHPN), being also important in kidney or heart transplants, where it was realized that quantitative changes in antigens in epithelial cells in colon or bladder neoplasms they usually correlate with the development of metastases [11]. Preliminary study data carried out by our research team, in 2020 in a public hospital, to assess the frequency of ABO / Rh blood groups and social conditions in patients with Chronic Renal Failure, showed that in those representing 140 surveyed patients, most belonging to group $056.4 \%$ (79/140), followed by patients from group A and B, who represented 20.7\% (29/140) and $17.9 \%$ (25/140) respectively, where gender most affected by renal failure, it was male, representing 51.4\% (72/140), with an average dialysis of 6.6 years, mostly from the north of the country, some had to travel for treatment, most affected municipalities Luanda and Viana (Figure 2).

\section{Chronic Renal Failure/Age}

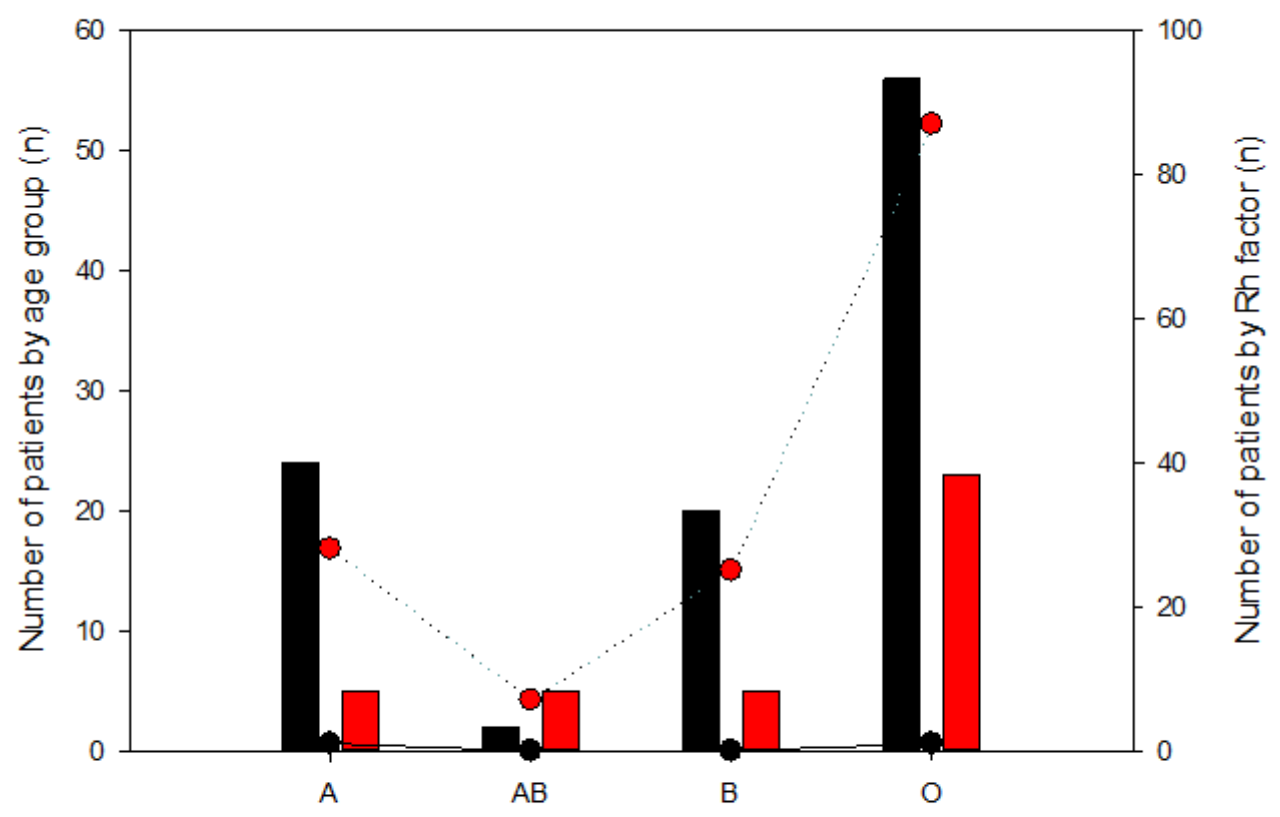

Blood Groups 
The incidence of chronic renal failure can be seen as shown in the figure 2. The present study also differs slightly from a survey in Shanghai to assess whether the ABO blood group is associated with renal outcomes in patients with IgA nephropathy, they found that patients in the non-B (type 0/A) group had lower GFR baseline, higher systolic blood pressure (SBP), uric acid, lactate dehydrogenase, highly sensitive C-reactive protein and tumour necrosis factor- $\alpha$ compared to patients in group B, which led them to conclude that patients with blood type $\mathrm{O}$ and $\mathrm{A}$ have an increased risk of deteriorating kidney function, which can be explained by a high level of inflammatory status [12] and a study from Ukraine that found that the highest probability of developing chronic kidney disease: glomerulonephritis with nephrotic syndrome was observed in carriers of the $\mathrm{ORh}+$ and $\mathrm{ABRh}+$ antigens [13].

\section{ABO/Rh Blood Groups, Nephrotic Syndrome,} and Sickle Cell Anaemia

Blood groups of patients with LECD (chronic discoid lupus erythematosus) have a frequency similar to that of the local population, however, disseminated clinical forms were more prevalent among group A patients, suggesting a possible indicator of disease prognosis [14], however, studies in Finnish and Iranian populations have not shown any significant difference in the distributions of $\mathrm{ABO}$ blood groups between patients undergoing revascularization surgery compared to the general population, in addition, cardiovascular mortality has been consistent with the increase in risk of thrombosis in blood groups 0 , due to the high plasma levels of von Willebrand factor [2].

Other preliminary data from studies developed by our research team, to assess the frequency of blood groups in patients with nephrotic syndrome (NS) and sickle cell anaemia (SC) and of the 100 surveyed patients, it was realized that the majority of the population belonged to the group Orh+, representing 42\% (21/50) for NS and 60\% (30/50) for SC, followed by patients in the ABrh+ group, representing 30\% (15/50) for NS and 34\% (17/50) for SC, the patients in the Arh+ and Brh+ groups, represented $26 \%(13 / 50)$ for NS and $6 \%(3 / 50)$ for SC, only one person $1 \%$ with NS, was in the ABrh- group, it was noticed that NS it affected the male gender in the same way as the female gender, however, SN affected the male gender more (Figure 3).

\section{Nephrotoxic Sidrome (NS) and Sickle Cell Anemia (SC)/Age}

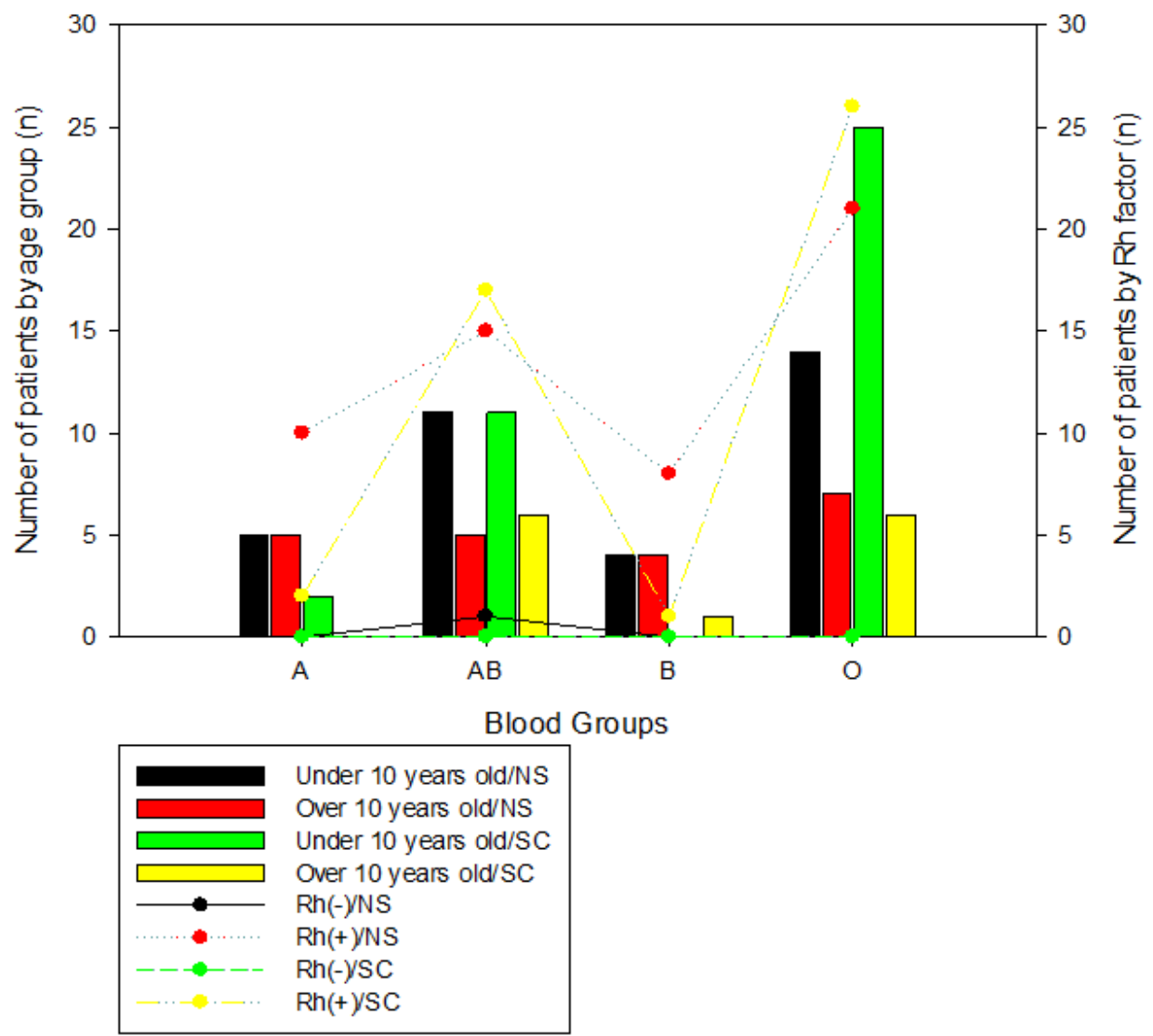

Figure 3: Nephrotic Sindrome (NS) and Sickle Cell Anemia (SC) and blood groups: patients with arterial hypertension were classified into two groups, the first of patients under 50 years of age and the second of patients over 50 years of age, to identify the frequency of blood groups and the Rh factor. 
The incidence of Nephrotic Sindrome and Sickle Cell Anaemia can be seen as shown in the Figure 3. It was noticeable in the study, that the patients in the ORh (+) group and represented the majority of the patients studied, both in patients with nephrotic syndrome (42\%) and in patients with sickle cell anaemia (60\%), followed by ABRh patients ( + ) which were also frequent in patients with nephrotic syndrome (32\%) and sickle cell anaemia (34\%), the first data was already expected, however for the second data it was a surprise because a study by our research team in the trace of sickle cell anaemia in Angola showed that the ORh (+) blood group was the most affected with $45 \%(6 / 13)$ of the participants, blood groups ARh (+) and ORh (+) together represented 60\% (15/25) of the heterozygous participants for the sickle cell trait (AS) [9].

\section{Conclusion}

Blood groups seem to vary depending on the type of pathologies, genders and ages, where it was noticed that blood group B patients over the age of 50 years, especially female, seem to be more susceptible to hypertension, patients in group 0 , followed by patients group $A$ and $B$, especially males are more susceptible to chronic kidney disease and patients in the Orh+ and ABrh+ groups are more susceptible to nephrotic syndrome in both genders and also to sickle cell anaemia, especially in males, however, more are needed studies to prove the hypotheses raised here.

\section{Conflict of interest statement}

The author states that the research was carried out in the absence of any commercial or financial relationships that could be interpreted as a potential conflict of interest.

\section{Acknowledgment}

The authors would like to thank the patients for their participation and the management and the workers from the Josina Machel Hospital for institutional support.

\section{References}

1. Dean L (2005) Blood Groups and Red Cell Antigens [Internet]. Bethesda (MD): National Center for Biotechnology Information (US).

2. Borges R, Velloso J, D ippolito J, Lopes J, Neto R, et al. (2014) Blood group association with diseases. Journal of Academic Works-Campus Niterói, North America 1(2): 1-5.

3. Borges SR, Velloso QJ, D Llpolito CA, Lopes MJ, Neto P, et al. (2019) Association of Blood Groups with Diseases.

4. Kessler CC (2019) ABO System/Biology.

5. Novaretti B, Carla A, Zago MC (2019) Molecular aspects of the ABO Blood System. Rev. Bras. Hematol. Hemoter 25 (1): 47-58.

6. (2010) BRAZILIAN HYPERTENSION SOCIETY. Clinical and laboratory evaluation and risk stratification.

7. Silva Rêgo A, Santos Laqui V, Gatez Trevisan F, Estevam Jaques A, Oliveira R R, et al. (2018) Factors associated with improper blood pressure in persons with hypertension. Cogitare Enfermagem 23(1): 1-10.

8. Fernandes M (2018) Twenty-percent-population-Angola-has-arterialhypertension-Interview granted to ANGOP.

9. Sacomboio E, Sebastião D, Filho Sacomboio F (2020) Sickle Cell Traitand Blood Groups (ABO and Rh) in Angolans Submitted to Hemoglobin Electrophoresis. Hematol Oncol Curr Res 2(1): 1-7.

10. Tortora GJ, Funke BR, Case C L (2012) Microbiology. 10(edn) Electronic data. - Porto Alegre: Artmed,. Edited.

11. Varrastro T, Lorenzi TF, Neto SW (2005) Hematology and Hematherapy; Fundamentals of morphology, physiology, pathology and Clinic. São Paulo: Editora Atheneu.

12. Yang M, Xie J, Ouyang Y, Zhang X, Shi M, et al. (2017) ABO blood type is associated with renal outcomes in patients with IgA nephropathy. Oncotarget 8(43): 73603-73612.

13. Vitalii K, Kovalchuk L, Yatsyshyn, Roman (2019) Assessment of associations between chronic kidney disease: glomerulonephritis with nephrotic syndrome and blood groups of AB0 and rhesus systems. Клінічна та профілактична медицина 3(9).

14. Tamega AA, Bezerra LVGSP, Pereira FP, Miot HA (2009) Blood groups and chronic discoid lupus erythematosus. An Bras Dermatol 84 (5): 477-81. 